\title{
Copper Oxide Nanoparticles Synthesis by Electrochemical Method
}

\author{
Nitin DIGHORE, Sunita JADHAV, Suresh GAIKWAD, Anjali RAJBHOJ *
}

\author{
Department of Chemistry, Dr. Babasaheb Ambedkar Marathwada University, Aurangabad - 431004 (M.S.) India \\ cross ${ }^{r e f}$ http://dx.doi.org/10.5755/j01.ms.22.2.7501
}

\section{Received 01 July 2014; accepted 31 January 2015}

\begin{abstract}
Copper oxide nanoparticles were prepared by electrochemical reduction method which is environmental benign. Tetra ethyl ammonium bromide (TEAB), tetra propyl ammonium bromide (TPAB), tetra butyl ammonium bromide (TBAB) were used as stabilizing agent in an organic medium viz. tetra hydro furan (THF) and acetonitrile (ACN) in 4:1 ratio by optimizing current density. The reduction process takes place under atmospheric condition over a period of $2 \mathrm{~h}$. Such nanoparticles were prepared using simple electrolysis cell in which the sacrificial anode was a commercially available copper metal sheet and platinum (inert) sheet acted as a cathode. The stabilizers were used to control the size of a nanoparticles. The synthesized copper oxide nanoparticles were characterized by using UV-Visible, FT-IR, XRD, SEMEDS and TEM analysis techniques.

Keywords: electrochemical method, current density, tetra alkyl ammonium bromide, copper oxide nanoparticles.
\end{abstract}

\section{INTRODUCTION}

Transition metal oxides are special class of semiconductors, which have number of applications in various fields. Copper (II) oxide is p-type semiconductor material with band gap $1.2-1.5 \mathrm{eV}$. The change in band gap is observed with temperature. The copper (II) oxide nanoparticles have attracted much more attention because promising applications in variety of areas including, solar cells [1], magnetic [2], field effect transistors [3], electrochemical cells [4], field emitters [5], thermoelectric materials [6,7], catalysis [8-11], sensors [12], superconductivity [13] and antimicrobial activity [14-15]. Recently it has attracted much more attention in photothermal \& photoconductive studies because being the base materials for synthesis of several high $\mathrm{T}_{\mathrm{C}}$ superconductors [16].

Copper (II) oxide nanoparticles have attracted much more interest in research compared to other noble metal nanoparticles because of their useful properties achievable at much less cost than silver and gold. The various methods of synthesis of copper NPs are by chemical [17], microwave irradiation [18], hydrothermal [19], electrochemical [20], biological [21], ultrasonic [22] and pulse laser ablation [23].

Realizing potential applications of copper (II) oxide nanoparticles here in we report a simple and fast preparation method for copper (II) oxide nanoparticles by electrochemical reduction method. For stabilization of copper (II) oxide nanoparticles, a series of tetra alkyl ammonium bromide salts have been used, which also control the particle size.

\section{EXPRIMENTAL DETAILS}

All chemical \& reagents were purchased from Aldrich. The metal foil required for electrochemical process of

\footnotetext{
${ }^{*}$ Corresponding author. Tel.: +91-240-2403311; fax: +91-240-2403335. E-mail address: anjali.rajbhoj@gmail.com (A. Rajbhoj)
}

thickness $0.25 \mathrm{~mm}$ and purity $99.9 \%$ were purchased from Alfa Asaer.

The synthesis of copper (II) oxide nanoparticles has been done by electrochemical reduction method originally reported by Reetz et. al. [24]. In the initial experiment we have used a copper metal sheet $(1 \times 1 \mathrm{~cm})$ as anode and a platinum sheet $(1 \times 1 \mathrm{~cm})$ as the cathode. These two electrodes were $1.0 \mathrm{~cm}$ apart. Tetra ethyl ammonium bromide (TEAB) $(0.01 \mathrm{M})$ in ACN/THF $(4: 1)$ served as the supporting electrolyte. Upon applying current density of $10 \mathrm{~mA} / \mathrm{cm}^{2}$ we obtained copper (II) oxide nanocluster stabilized by TEAB. Copper (II) oxide nanoparticles were found to be dark brown in colour. The reaction proceeds same way for stabilizer TPAB and TBAB. Since the nanoparticles are insoluble in solvent used the work up only needed simple decantation. The decanted solid copper (II) oxide nanoparticles were wash with dry THF three to four times to remove excess stabilizers and drying in vacuum they were then stored as closed glass vials for characterization.

The prepared copper(II) oxide nanoparticles were characterized by UV-Visible spectrophotometer, FT-IR spectrophotometer, XRD, TEM, SEM-EDS techniques. The UV-visible spectra were recorded on UV-Visible spectrophotometer [JASCO 503] using a quartz cuvette with ACN/THF $(4: 1)$ as reference solvent. The IR spectra were recorded on FT-IR spectrophotometer [JASCO, FT-IR/4100] Japan using dry $\mathrm{KBr}$ as standard reference in the range of $600-4000 \mathrm{~cm}^{-1}$. The X-ray powder diffraction patterns of the copper oxide nanoparticles were recorded on Bruker 8D advance X-ray diffractometer using $\mathrm{CuK \alpha}$ radiation of wavelength $=1.54056 \AA$. To study the morphology and elemental composition copper (II) oxide nanoparticles were examined using SEM and energy dispersive spectrophotometer (EDS). The SEM analysis was carried out with JEOL; JSM-LA operated at $20.0 \mathrm{kV}$ and $1.0000 \mathrm{nA}$. Shape, size and morphology ware calculated by TEM analysis was using Philips model CM200 operated at $200 \mathrm{kV}$. 


\section{RESULTS AND DISSCUSSION}

The reduction of copper ions visibly evident from color change associated with it. Fig. 1 shows the copper (II) oxide nanoparticles showed a peak at about $640 \mathrm{~nm}$. The greenish colour obtained gradually changed to brownish black indicating copper being oxidized to zero to $2+$ oxidation state. Copper (II) oxide nanoparticles exhibits maximum absorption at $638-642 \mathrm{~nm}$. This absorption band can be attributed to the surface plasmon resonance peak of copper (II) oxide nanoparticles. The SPR of colloidal copper oxide nanoparticles reported previously [25] with a broad peak at $590-640 \mathrm{~nm}$ is in agreement with the present result. A broad peak around $640 \mathrm{~nm}$ can be attributed to agglomeration and wide size distribution of nanoparticles in the solution. The particles showed hardly any change in the absorption spectra even after a month of ageing time, which indicates the highly stable nature of copper (II) oxide nanoparticles.

Fig. 2 represents IR spectra of copper (II) oxide nanoparticles capped with a-TEAB, b-TPAB and $\mathrm{c}-$ TBAB of $0.01 \mathrm{M}$ solution at $10 \mathrm{~mA} / \mathrm{cm}^{2}$ current density. In IR spectrum peak appears at $3424-3437 \mathrm{~cm}^{-1}$ which can be attributed to the hydroxyl groups, which indicate hygroscopic nature of copper (II)oxide nanoparticles. Peaks at $2962-2975 \mathrm{~cm}^{-1}, 2872-2885 \mathrm{~cm}^{-1}$ and $1587 \mathrm{~cm}^{-1}$ are due to the $\mathrm{C}-\mathrm{H}$ stretching \& bending respectively. $1664 \mathrm{~cm}^{-1}$ is peak due to $\mathrm{N}^{+} \mathrm{R}_{4}$ symmetrical ion. Peak at $1386-1399 \mathrm{~cm}^{-1}$ is due to the C-C stretching and at $1069 \mathrm{~cm}^{-1}$ is due to $\mathrm{C}-\mathrm{N}$ stretching. Some of the peaks reflect in the range of $752-880 \mathrm{~cm}^{-1}$ that might be due to bending mode of vibrations of $\mathrm{M}-\mathrm{O}-\mathrm{M}$ bending $(\mathrm{M}=\mathrm{Cu})$. The peak at $659-690 \mathrm{~cm}^{-1}$ due to stretching of mode of vibration of $\mathrm{Cu}-\mathrm{O}$. In general from TEAB to TBAB increase in wavenumber was noticed from 3424 to 3437 , 2962 to 2975,2872 to 2885,752 to 760 and $659-690 \mathrm{~cm}^{-1}$. In order to understand the phase symmetry of copper (II)oxide nanoparticles a systematic study on the XRD studies was undertaken. Fig. 3 shows XRD pattern of copper(II)oxide nanoparticles capped with $0.01 \mathrm{M}$ concentration a-TEAB, b-TPAB, c-TBAB at $10 \mathrm{~mA} / \mathrm{cm}^{2}$ current density. The lattice parameters $\mathrm{a}=4.653, \mathrm{~b}=3.410, \mathrm{c}=5.4089$ at $\beta=99.480$. The strong and sharp peaks were obtained at planes (-111), (111), (012), (020), (120) and (121) indicating the monoclinic structure of copper (II) oxide nanoparticles which were found to be highly crystalline in nature. The diffraction is in good co-ordination with the ASTM card No. 74-1021. The average particles size calculated were in the range of 5-25 nm using Debye Scherrer [26] Eq. 1, indicating high surface area. The surface area to volume ratio of nanocrystals is given by

$d=\frac{K \lambda}{\beta \cos \theta}$,

where $K$ known as Scherrer's constant (shape factor), ranging from 0.9 to $1.0 ; \lambda$ which is the wavelength of the $\mathrm{X}$-ray radiation source is $1.5418, \beta$ is the full width of the peak at half height and $\theta$ is Bragg angle.

XRD plots show the intense peaks of TEAB, TPAB, TBAB for (111) plane the full width of half maximum
(FWHM) value were 1.3818, 1.4097 and 1.5609 increases with decreasing the particle in size $6.04 \mathrm{~nm}, 5.92 \mathrm{~nm}$ and $5.34 \mathrm{~nm}$ respectively as shown in Table 1 .

To study the surface morphology and elemental composition, the SEM with EDS were investigated systematically. Fig. $4 \mathrm{a}-\mathrm{c}$ shows that nanoparticles have irregular shape and the distribution was not uniform, which was probably due to the partial solubility of the surfactant in the solvent in experimental condition. Fig. 4 a, b shows presence of porous nanoparticles that agglomerated irregularly. Fig. $4 \mathrm{c}$ shows SEM microstructure of copper (II) oxide nanoparticles capped with TBAB with dense agglomerations. The EDS spectrum was used to analyzed the composition of copper (II) oxid nanoparticles and the result are shown in Fig. $4 \mathrm{~d}$, the peaks for the elements of $\mathrm{C}, \mathrm{O}, \mathrm{Br}$ and $\mathrm{Cu}$ observed discribe in Table 2. The peak for $\mathrm{Br}$ arises as the impurity from surfactants, which present in trace amount.

The micrograph of Fig. $5 \mathrm{a}-\mathrm{c}$, shows that consists of spherical nanoparticles with a regular morphology and average size of the particles was in the range of 5-30 nm, which were good agreement with crystalline size from XRD. The histogram in Fig. $5 \mathrm{a}-\mathrm{c}$ showed that the average mean size and standard deviation of copper (II) oxide nanoparticles capped with a-TEAB, b-TPAB and $\mathrm{c}-\mathrm{TBAB}$ as $28.79 \pm 9.26 \mathrm{~nm}, \quad 22.39 \pm 5.86 \mathrm{~nm}$ and $13.29 \pm 6.93 \mathrm{~nm}$ respectively, represent the aggregated copper (II) oxide nanocrystals. The SAED images inset of Fig. $5 \mathrm{a}-\mathrm{c}$ shows the copper (II) oxide nanoparticles are well crystalline in nature. The diffraction rings on picture correspond to (-111) and (111) respectively which is in accordance with XRD pattern.

Table 1. The effect of stabilizer on size of copper (II) oxide nanoparticles

\begin{tabular}{|l|c|c|c|c|}
\hline $\mathrm{Cu}$ NPs & $2 \theta$ & h k 1 & FWHM & Size, $\mathrm{nm}$ \\
\hline $\mathrm{Cu}-\mathrm{TEAB}$ & 38.37 & 111 & 1.3818 & 6.04 \\
\hline $\mathrm{Cu}-\mathrm{TPAB}$ & 38.56 & 111 & 1.4097 & 5.92 \\
\hline $\mathrm{Cu}-\mathrm{TBAB}$ & 38.65 & 111 & 1.5609 & 5.34 \\
\hline
\end{tabular}

Table 2. Elemental compositions from EDS of TBAB stabilized copper (II) oxide nanoparticles

\begin{tabular}{|c|c|c|c|}
\hline Elements & $\mathrm{KeV}$ & Mass, \% & Atom, \% \\
\hline $\mathrm{C} \mathrm{K}$ & 0.277 & 7.64 & 26.80 \\
\hline $\mathrm{O} \mathrm{K}$ & 0.525 & 6.24 & 16.43 \\
\hline $\mathrm{CuK} 1$ & 8.840 & 84.02 & 55.67 \\
\hline $\mathrm{BrL}$ & 1.480 & 2.10 & 01.11 \\
\hline
\end{tabular}

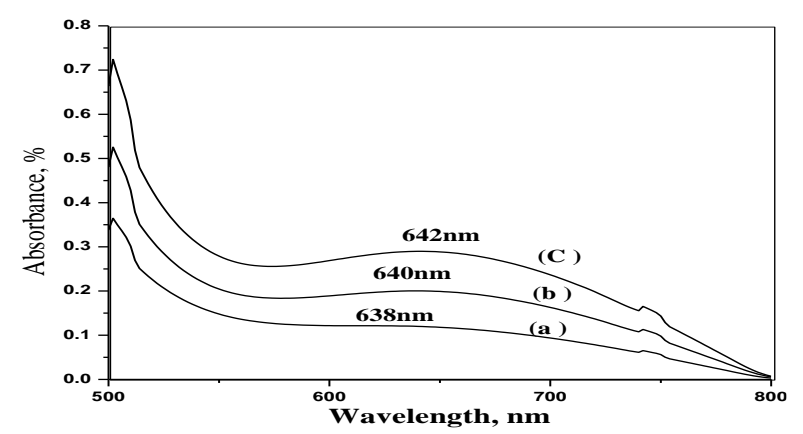

Fig. 1. UV-visible spectra of copper (II) oxide nanoparticles: $\mathrm{a}-\mathrm{TEAB} ; \mathrm{b}-\mathrm{TPAB} ; \mathrm{c}-\mathrm{TBAB}$ of $0.01 \mathrm{M}$ sollution at $10 \mathrm{~mA} / \mathrm{cm}^{2}$ current density 


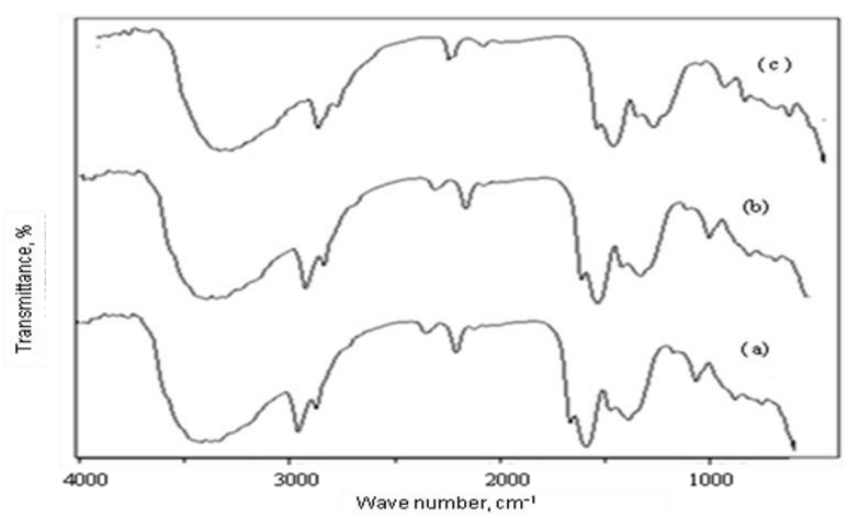

Fig. 2. FT-IR spectra of copper (II) oxide nanoparticles: $\mathrm{a}-\mathrm{TEAB} ; \mathrm{b}-\mathrm{TPAB} ; \mathrm{c}-\mathrm{TBAB}$ at $10 \mathrm{~mA} / \mathrm{cm}^{2}$ current density

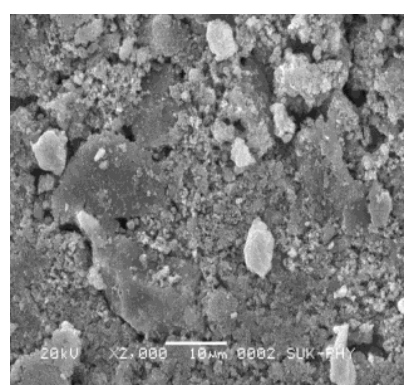

a

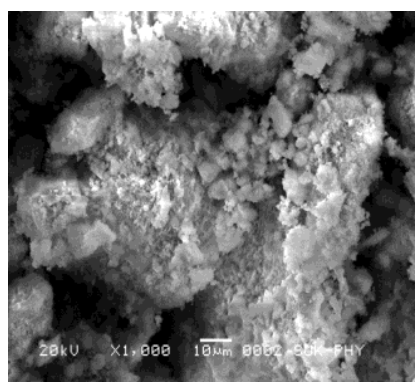

b

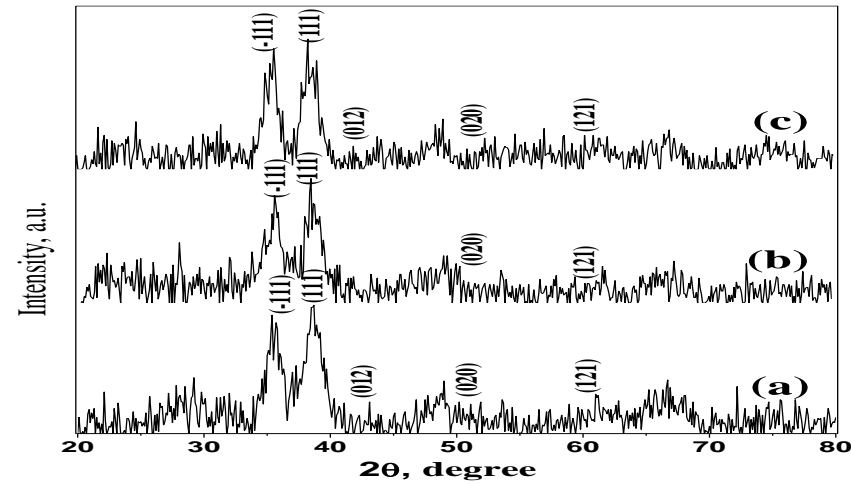

Fig. 3. XRD patterns of copper (II) oxide nanoparticles: aTEAB;b-TPAB; c-TBAB at $10 \mathrm{~mA} / \mathrm{cm}^{2}$ current density

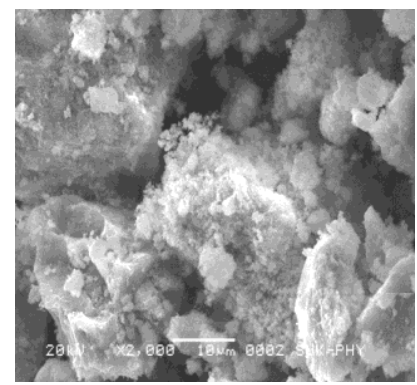

c

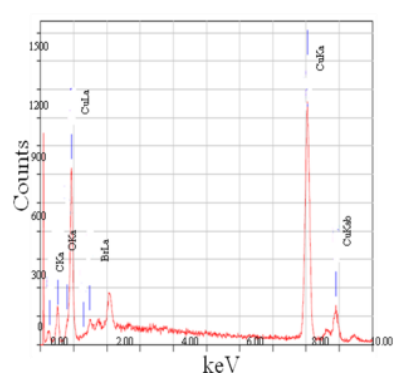

d

Fig. 4. SEM images of copper (II) oxide nanoparticles: $a-T E A B ; b-T P A B ; c-T B A B$ at $10 \mathrm{~mA} / \mathrm{cm}^{2}$ current density; d-EDS spectra of TBAB
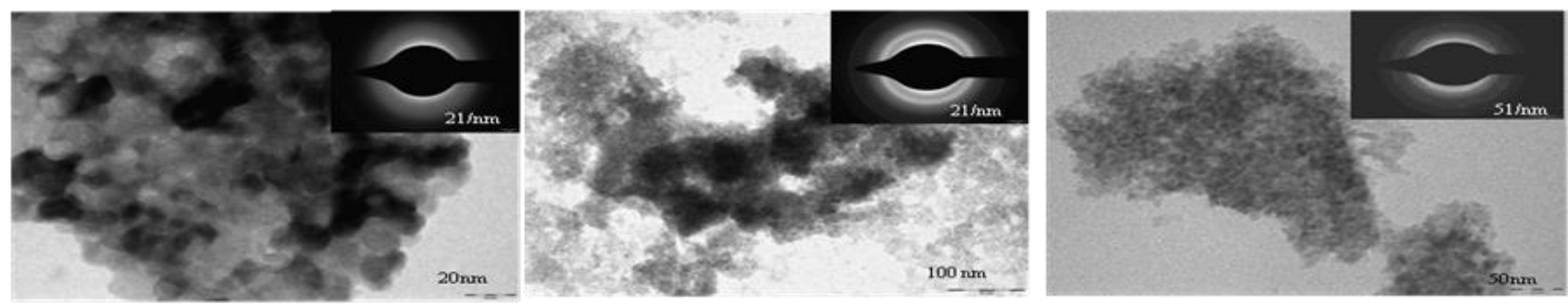

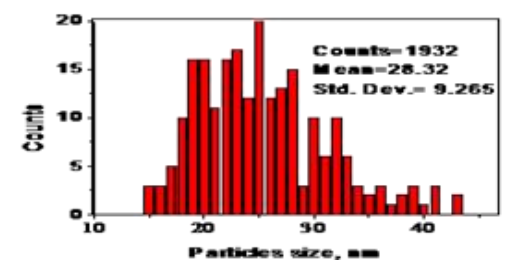

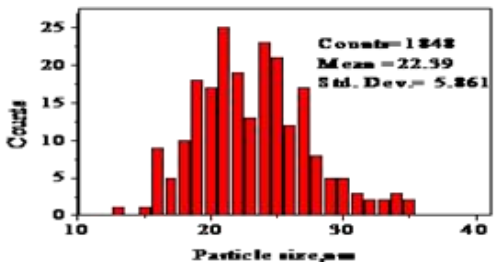

b

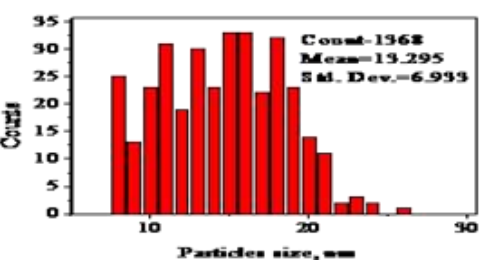

Fig. 5. TEM images inset with SAED pattern and respective histogram of copper (II) oxide nanoparticles: $a-T E A B$; $b-T P A B$; $\mathrm{c}-\mathrm{TBAB}$ at $10 \mathrm{~mA} / \mathrm{cm}^{2}$ current density

\section{CONCLUSIONS}

We have demonstrated the efficiency of electrochemical reduction method for the synthesis of spherical shaped copper (II) oxide nanoparticles. The TEAB, TPAB and TBAB salts used as stabilizing agents have played significant role on controlling the particle size. There is effect of stabilizers on particle size of copper (II) oxide nanoparticles the size decreases with increasing carbon chain in TEAB, TPAB and TBAB of respective salts confirmed by XRD \& TEM data. The copper (II) oxide nanoparticles had average size in the range of 5 $30 \mathrm{~nm}$ and has monoclinic structure. Thus the synthesis of
copper(II) oxide nanoparticles by electrochemical reduction method is easiest, cheapest, require less time and high purity of nanoparticles are obtained.

\section{Acknowledgments}

The authors are grateful do Department of Chemistry, Dr. Babasaheb Ambedkar Marathwada University, Aurangabad and UGC-SAP-DRS-1 scheme New Delhi for providing laboratory facility. One of the author (ASR) thankful for financial assistance from Major Research project [F. No. 832/2010(SR)], University Grants Commission, New Delhi, India. 


\section{REFERENCES}

1. Kidowaki, H., Oku, T., Akiyama, T., Suzuki, A., Jeyadevan, B., Cuya, J. Fabrication and Characterization of CuO-based Solar Cells Journal of Material Science Research 1 2012: pp. 138-143.

2. Dar, M. A., Kim, Y. S., Kim, W. B., Sohn, J. M., Shin, H. S. Structural and Magnetic Properties of $\mathrm{CuO}$ Nanoneedles Synthesized by Hydrothermal Method Applied Surface Science 254 2008: pp. 7477-7481.

3. Liao, L., Zhang, Z., Yan, B., Zheng, Z., Bao, Q. L., Wu, T., Li, C. M., Shen, Z. X., Zhang, J. X., Gong, H., Li, J. C., Yu, T. Multifunctional CuO Nanowire Devices: ptype Field Effect Transistors and CO Gas Sensors Nanotechnology 20 2009: pp. 1-6.

4. Bushong, W., Destephen, M., Jin, Z., Ndzebet, E., Kennedy, J., Ramaswami, K., Scherer, J., Boone, D., Mortensen, E., Gilbert, D., Vub, V. New Alkaline Electrochemical Cells Using Stabilized CuO-CuS Cathodes ECS Transactions 1 2007: pp. 14-25.

5. Hsieh, C. T., Chen, J. M., Lin, H. H., Shih, H. C. Field Emission from various $\mathrm{CuO}$ Nanostructures Applied Physics Letter 83 2003: pp. 3383-3385. http://dx.doi.org/10.1063/1.1619229

6. Koumoto, K., Koduka, H., Seo, W. S. Thermoelectric Properties of Single Crystal $\mathrm{CuAlO}_{2}$ with a layered structure Journal Material Chemistry 11 2001: pp. 251-252. http://dx.doi.org/10.1039/b006850k

7. Lee, S., Choi, U. S., Li, S., Eastman, J. A. Measuring Thermal Conductivity of Fluids Containing Oxide Nanoparticles Journal of Heat Transfer 121 1999: pp. 280-289.

8. Zhang, J., Yu, C., Wang, S., Wan, C., Wang, Z. A Novel and Efficient Methodology for the Construction of Quinazolines based on Supported Copper Oxide nanoparticles Chemical Communication 46 2010: pp. 5244-5246. http://dx.doi.org/10.1039/c002454f

9. Ma, D., Cai, Q., Zhang, H. Mild Method for Ullmann Coupling Reaction of Amines and Aryl Halides Organic Letters 5 2003: pp. 2453-2455.

10. Samim, M., Kaushik, N., Maitra, A. Effect of size of Copper Nanoparticles on its Catalytic Behaviour in Ullman Reaction Bulletin of Material Science 30 2007: pp. $535-540$.

11. Puri, S., Kaur, B., Parmar, A., Kumar, H. Copper Perchlorate Hexahydrate: An Efficient Catalyst for the Green Synthesis of Polyhydroquinolines under Ultrasonication ISRN Organic Chemistry 2011 2011: pp. $1-4$.

12. Sharma, S., Nirkhe, C., Pethkar, S., Athawale, A. Chloroform Vepour Sensor based on Copper/ Polyaniline Nanocomposite Sensor and Actuators B 8 2002: pp. $131-136$. http://dx.doi.org/10.1016/S0925-4005(02)00064-3

13. Chen, G., Langlois, J., Guo, Y., Goddard, W. Superconducting Properties of Copper Oxide
Proceedings of the National Academy of Sciences USA 86 1989: pp. 3447-3451.

14. Ramydevi, J., Jayasubramanian, K., Marikani, A., Rajkumar, G., Rehuman, A. Synthesis and Antimicrobial Activity of Copper Nanoparticles Material Letters 71 2012: pp. $114-116$

15. Chattergee, A., Sarkar, R., Chattopadhyaya, A., Aich, P., Basu, T. A Simple Robust Method for Synthesis of Metallic Copper Nanoparticles of High Antibacterial Potency against E. coli Nanotechnology 23 2012: pp. 1-11.

16. Forysth, J. B., Brown, P. J., Wanklyn, B. M. Magnetism in Cupric Oxide Journal of Physics C: Solid State Physics 21 1988: pp. 2917-2929. http://dx.doi.org/10.1088/0022-3719/21/15/023

17. Usman, M., Ibrahim, N., Shameli, K., Zainuddin, N. W., Yanus, W. Copper Nanoparticles Mediated by Chitosan: Synthesis and Characterization via Chemical Methods Molecules 17 2012: pp. 14928-14936.

18. Wang, H., Xu, J., Zhu, J., Chen, H. Preparation of $\mathrm{CuO}$ Nanoparticles by Microwave Irradiation Journal of Crystal Growth 244 2002: pp. 88-94.

19. Outokesh, M., $\quad$ Hosseinpour, M., $\quad$ Ahmadi, S. J., Mousavand, T., Sadjadi, S., Soltanian, W. Hydrothermal Synthesis of $\mathrm{CuO}$ Nanoparticles: Study on Effects of Operational Conditions on Yield, Purity, and Size of the Nanoparticles Industrial \& Engineering Chemistry Research 50 2011: pp. 3540-3554.

20. Gao, T., Meng, G., Wang, Y., Sun, S., Zhang, L. Electrochemical Synthesis of Copper Nanowires Journal Physics Condensed Matter 14 2002: pp. 355-363. http://dx.doi.org/10.1088/0953-8984/14/3/306

21. Rahman, A., Ismail, A., Jumbanti, D., Magdalena, S., Sudrajat, H. Synthesis of Copper Oxide Nanoparticles by using Phormidium Cyanobacterium Indonesian Journal of Chemistry 9 2009: pp. 355-360.

22. Pandey, V., Mishra, G., Verma, S. K., Wan, M., Yadav, R. R. Synthesis and Ultrasonic Investigations of CuO-PVA Nanofluid Materials Sciences and Applications 3 2012: pp. 664-668.

23. Swarnkar, R., Singh, S., Gopal, R. Effect of aging on CopperNanoparticles Synthesized by Pulsed Laser Ablation in Water: Structural and Optical Characterizations Bulletin of Material Science 34 2011: pp. 1363-1369. http://dx.doi.org/10.1007/s12034-011-0329-4

24. Reetz, M., Helbig, W., Quaiser, S. Electrochemical Preparation of Nanostructured Bimetallic Clusters Chemistry Material 7 1995: pp. 2227-2228.

25. Yao, W., Yu, S., Zhou, Y., Jiang, J., Wu, Q., Zhang, L., Jiang, J. Formation of Uniform $\mathrm{CuO}$ Nanorods by Spontaneous Aggregation: Selective Synthesis of $\mathrm{CuO}$, $\mathrm{Cu} 2 \mathrm{O}$, and $\mathrm{Cu}$ Nanoparticles by a Solid-Liquid Phase arc Discharge Process Journal of Physical Chemistry B 109 2005: pp. $14011-14016$. http://dx.doi.org/10.1021/jp0517605

26. Klug, H., Alexander, L. X-ray Diffraction Procedures, Wiley, New York, 1962. 